Check for updates

Cite this: RSC Adv., 2019, 9, 29414

Received 21st July 2019

Accepted 9th September 2019

DOI: $10.1039 / c 9 r a 05637 h$

rsc.li/rsc-advances

\section{Highly efficient solar seawater desalination with environmentally friendly hierarchical porous carbons derived from halogen-containing polymers $\dagger$}

\author{
Fenghua Liu, (iD a Lijian Wang, (iD) a Robert Bradley, ${ }^{\text {bc }}$ Binyuan Zhao (D) *a \\ and Weiping Wu iD *d
}

\begin{abstract}
Desalination of seawater using solar energy is a promising solution to the global freshwater shortage. Ultrahigh surface area (up to $1740 \mathrm{~m}^{2} \mathrm{~g}^{-1}$ ) hierarchical porous carbons (HPC) have been prepared by the carbonization of precursors derived from the room temperature dehalogenation of low cost, widely available polyvinyl chloride (PVC) with simple, low cost, environmentally friendly processes. The broad hierarchical pores (from $2 \mathrm{~nm}$ to $20 \mu \mathrm{m}$ ) facilitate and ensure fast water and vapor transportation. Flexible photothermal steam generation devices were successfully fabricated with these hierarchical porous carbons on hydrophilic ultrathin $(200 \mu \mathrm{m})$ paper. An evaporation rate record of $7.87 \mathrm{~kg} \mathrm{~m}^{-2} \mathrm{~h}^{-1}$ and high energy conversion of $95.8 \%$ have been obtained under the concentrated solar intensity of $5 \mathrm{~kW}$ $\mathrm{m}^{-2}$. Our research leads to a new approach to converting halogenated plastics into environmentally friendly and useful porous carbon materials by simple, low-cost processes. It establishes and validates the concept of creating a sustainable and economic pathway to simultaneously recycle halogenated polymers, harvest solar energy and produce clean freshwater.
\end{abstract}

\section{Introduction}

Freshwater and clean energy are critical resources for the future of the planet. Due to the pressures of growing populations and climate changes, the supply of fresh water is becoming an increasingly severe problem. Seawater desalination is known as an effective way to solve the shortage of freshwater resources in the world. Recently, solar vapour generation using free, renewable energy to achieve efficient seawater desalination has been recognized as a very valuable potential idea to solve the problem of the shortage of freshwater resources., ${ }^{1,2}$ Optimized thermal management and water supply can greatly enhance the energy conversion efficiency. To this end, various materials ${ }^{3-7}$ were investigated by researchers. Typical nanoparticles, silver, ${ }^{8}$ gold ${ }^{9,10}$ and aluminium, ${ }^{11}$ together with nano metal oxides ${ }^{12}$ and carbide ${ }^{13}$

${ }^{a}$ State Key Laboratory of Metal Matrix Composites, School of Materials Science and Engineering, Shanghai Jiao Tong University, Shanghai, 200240, China. E-mail: byzhao@sjtu.edu.cn

${ }^{b}$ Department of Materials, University of Oxford, 16 Parks Road, Oxford, OX1 3PH, UK 'MatSurf Ltd, The Old Stables Marion Lodge, Little Salkeld, Penrith, Cumbria, CA10 $1 N W, U K$

${ }^{d}$ Department of Electrical and Electronic Engineering, School of Mathematics, Computer Science and Engineering, City, University of London, Northampton Square, London, EC1V OHB, UK. E-mail: Weiping.Wu@city.ac.uk

$\dagger$ Electronic supplementary information (ESI) available. See DOI: $10.1039 / \mathrm{c} 9 \mathrm{ra} 05637 \mathrm{~h}$ which show remarkable plasmonic effect have good performance in absorbing the solar energy. Graphene, ${ }^{14,15}$ carbon-nanotubes, ${ }^{16-18}$ carbon sponge, ${ }^{19}$ graphdiyne, ${ }^{20}$ and carbon composite materials also have been studied. The key limiting factor of the absorption of light, the transmission of water and the escape of water vapour is the microstructure of these carbon materials.

Chlorine $(\mathrm{Cl})$ is one of the most dangerous elements that induce environmental problems. The chlorine in organic compounds and polymers can be converted into inorganic acids and persistent toxic organic pollutants, such as dioxins accumulate in the food chain, causing several types of cancer. Polyvinyl chloride (PVC), the second largest resin, is produced exceeds 50 million tonnes per year globally. Pure PVC consists of $57 \%$ chlorine by weight, chlorine in PVC makes green recycling of PVC be more difficult, expensive and incompatible with the recycling of non halogen-containing plastics.

Conventional porous carbon materials usually have pore sizes in the range of $1 \mathrm{~nm}$ to $5 \mathrm{~nm}$. So far there had been very little understanding on how pore sizes will influence the solar vapour generation performances, or if there is any mass transfer upper limit, mainly due to the difficulties of producing porous black materials with larger pores. Despite that many materials could realize satisfied solar-thermal conversion, the disadvantages especially of high cost (noble metals) and environmental hazards of many nanomaterials used, will largely limit the practical applications of these materials. Therefore, to develop 
high-efficiency photothermal conversion materials that are inexpensive, environmentally and capable of large-scale applications is currently the biggest challenge.

Large pore sized carbon materials are ideal due to their high optical absorption over the broad spectrum of sunlight, and the unique structures to achieve better water supply balance and maximize water vapour escape. This becomes much more important when applying porous carbon materials in higher performance solar thermal devices or in systems designed for concentrated solar intensities. It has been well known that carbon fibers, carbon nanotubes and graphene could be prepared by using polymers which have long chain structure and high carbon density to promote aromatic cyclization with lower energy as the precursors. However, only oxygencontaining and nitrogen-containing polymers have been widely used as precursors for carbonization, polymers with halogen elements were rarely used for the preparation of high surface area carbon materials.

In this paper, we describe a new hierarchical porous carbon (HPC), prepared by mechanochemical dehalogenation of PVC at room temperature followed by low-temperature carbonization, for use in high-efficiency water vapour (steam) generation. As we all know, PVC waste has a very high risk to the environment. Fortunately, chlorine atoms can be removed with less energy by reacting with strong alkaline in halogenated polymers. ${ }^{21} \mathrm{We}$ use polyvinyl chloride (PVC) as the raw material to produce the porous carbon and coated it on paper as the ultrathin solar absorber. We developed a simple method that enables complete dechlorination of PVC, and achieved high efficiency for solar generation by using this material. Thus, the newly developed dehalogenation process of halogenated polymers provides an inexpensive, simple, and environmentally friendly solution of producing desirable carbon materials at large scale.

\section{Experimental section}

\section{Materials and chemicals}

All chemicals and solvents in the experiments were of analytical grades. Sodium chloride $(\mathrm{NaCl})$, calcium chloride $\left(\mathrm{CaCl}_{2}\right)$, potassium chloride $(\mathrm{KCl})$ and magnesium sulfate $\left(\mathrm{MgSO}_{4}\right)$, $\mathrm{KOH}, \mathrm{PVC}, \mathrm{DMF}$ ( $N, N$-dimethylformamide) were purchased from Sigma-Aldrich. Air-laid paper was purchased from Kimberly-Clark Corporation. Deionized water with an electrical resistivity of $18.2 \mathrm{M} \Omega \mathrm{cm}$ was generated from a TTL-30C Ultrapure Water Generator.

\section{Fabrication of HPC device}

Typically, $1.00 \mathrm{~g}$ PVC, $1.68 \mathrm{~g}$ (30 mmol) KOH and $10 \mathrm{~mL}$ DMF were mixed together, followed by hand grinding for 10, 20, 30 and 40 minutes, and named HPC-1, HPC-2, HPC-3 and HPC-4, respectively. After that, the raw materials were transferred into a vacuum oven overnight at $70{ }^{\circ} \mathrm{C}$ for drying and then annealed at $700{ }^{\circ} \mathrm{C}$ under argon protection for 2 hours. Then, the products were hand ground again and then washed to be neutral. Finally, the HPC device can be prepared by filtration on the airlaid paper.

\section{Characterizations}

The SEM analysis was conducted by a field-emission scanning electron microscopy (SEM, FEI Sirion 200, $5 \mathrm{kV}$ ). The mesoporous and microporous structures were investigated using a field-emission transmission microscope (TEM, Talos F200X). The Raman spectra were detected using a dispersive Raman microscope (Senterra R200-L) with a $532 \mathrm{~nm}$ laser excitation. The X-ray Photoelectron Spectroscopy (XPS) analyses were carried out on Kratos AXIS Ultra DLD. The FTIR spectra were recorded on a Nicolet 6700 Fourier Transform Infrared (FTIR) spectrometer. The surface areas of the HPC samples were measured by a TriStar 3000 surface area analyser (Micromeritics) by nitrogen $\left(\mathrm{N}_{2}\right)$ adsorption Brunauer-Emmett-Teller (BET) tests. The macropores features were detected by mercury intrusion porosimetry (Thermo Scientific Pascal 140/240). Thermo-gravimetric analyses (TGA) of HPC samples were performed by a thermo-gravimetric analyser (NETZSCH STA 449F3). The samples of about $5 \mathrm{mg}$ were heated in the air with temperature range from $40{ }^{\circ} \mathrm{C}$ to $910{ }^{\circ} \mathrm{C}$ at the heating rate of $10{ }^{\circ} \mathrm{C} \min ^{-1}$. The optical spectra (reflection and transmission) of the HPC samples were measured from $250 \mathrm{~nm}$ to $2500 \mathrm{~nm}$ by a UV-Vis NIR Spectrometer (PerkinElmer, Lambda 750S, USA) equipped with an integrating sphere. The absorption was calculated by $A=1-R-T$, where $A, R$ and $T$ are the absorption, the reflection and the transmission, respectively. The infrared mappings and the temperature distributions were captured by using an IR camera (MAG32, Magnity Electronics, China).

\section{Solar evaporation tests}

Simulated seawater $(3.5 \mathrm{wt} \% \mathrm{NaCl})$ was prepared in a $100 \mathrm{~mL}$ glass beaker. A HPC device coated on a polystyrene foam was placed into the water which can float on the simulated seawater. The HPC device can cover almost the surface of the water and the edges were carefully sealed by polystyrene foam and aluminium foil to avoid the natural evaporation through the residual uncovered water surface. The collimated beam (diameter: $10 \mathrm{~cm}$ ) was supplied by a solar simulator (Newport Oriel 94043 AAA). A piece of Fresnel lens $(26 \mathrm{~cm} \times 18 \mathrm{~cm}$, focal length: $300 \mathrm{~mm}$, OpticLens) was used to concentrate the sunlight beam. The solar light was measured and calibrated using an optical power meter (S310C, Thorlabs Inc.). The beaker with water and the HPC device were placed on an analytical balance, which can monitor the mass loss of water in real time.

\section{Results and discussion}

\section{Morphologies and properties}

The precursor for HPCs material can be obtained by mechanochemical grinding, illustrated in Fig. 1a (details showed in Experimental section). The preparation can be divided into two steps: dechlorination and carbonization. The dehalogenation and elimination chemical reactions, have been widely used in the synthesis of polymers, organic compounds and inorganic materials. ${ }^{22}$ The dechlorination process can be activated by applying mechanical stress, so that mechanochemical methods such as hand grinding, bead milling, neat grinding, liquid- 

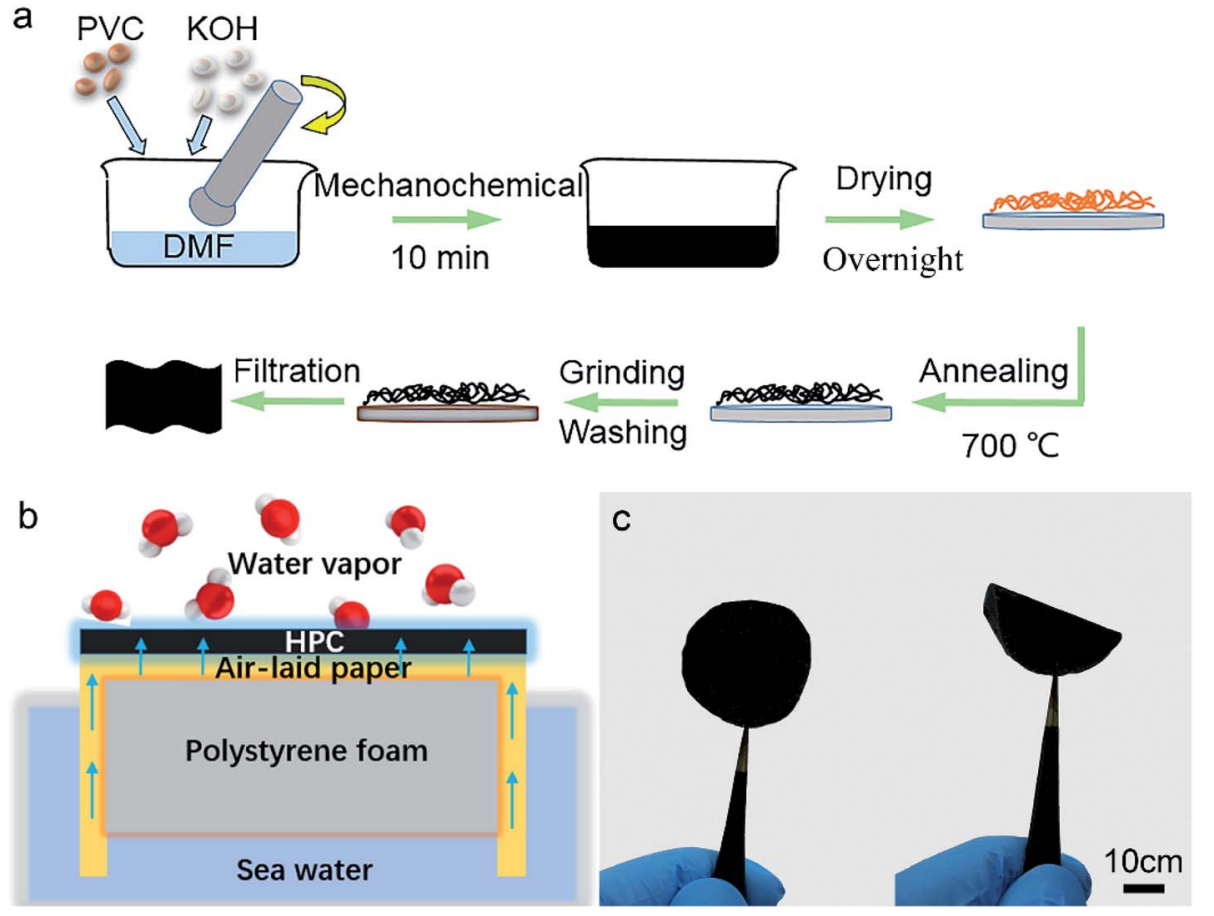

Fig. 1 Preparation and schematic diagram of the hierarchical porous carbons (HPC). (a) The preparation of HPC from the dehalogenation of polyvinyl chloride (PVC), the fabrication of flexible HPC-paper photothermal devices. (b) A schematic diagram of the mass transportation and thermal transportation in the photothermal device floating on seawater. (c) Photographs of flat and bent status of an HPC-paper device.

assisted grinding, kneading and ball milling can help the removal of the $\mathrm{Cl}$ element from the PVC effectively. The colour of the mixture containing DMF, $\mathrm{KOH}$ and PVC turned to yellow, then brown and finally black (Fig. S1, ESI†). The carbonization was performed at $700{ }^{\circ} \mathrm{C}$ under argon (Ar) atmosphere. Following that, the carbon materials were dispersed in water and coated on a piece of $200 \mu \mathrm{m}$ think non-woven paper, to form the black, thin and porous surface served as the solar absorber.

The heat transportation behaviour of the HPC-paper solar energy vapour generation device is explained in Fig. $1 \mathrm{~b}$, and a photo is shown in Fig. 1c. The seawater can be quickly transported by air-laid paper to the top HPC layer which localized much solar energy. The dark and porous HPC can absorb solar energy very fast and its multi-porous structure with good hydrophilic also can absorb water from the bottom paper. When the water reached the hot zone of the HPC layer, the water molecules can be heated and evaporated, and then finally collected.

The resultant HPC materials were subjected to microscopic characterizations. Fig. 2a-c exhibits a typical morphology image of HPC using scanning electron microscope (SEM), showing amorphous porous structures. From the SEM pictures, the porous structures can be revealed clearly, consisting of $200 \mathrm{~nm}$ to $2.5 \mu \mathrm{m}$ intercommunicating pores and it can be clearly observed these connected porous structures are spread throughout the HPC materials.

The pore structure characteristics were further observed by transmission electron microscope (TEM). From Fig. 2d-f, it can be found that the HPC materials also have a partial mesoporous structure with the pore size below $50 \mathrm{~nm}$. This macro and mesopores can be explained by the activation of the excessive $\mathrm{KOH}$ in the carbonization at high temperature (annealing, 700 ${ }^{\circ} \mathrm{C}$ ), which can maximize the micropore content. In addition, the by-product $\mathrm{KCl}$ can further promote the expansion of the pore structure as hard-template. The HPC materials with hierarchical porous structure especially the abundant macroporous structure provide ideal channels for supplying water and vapour escape.

The surface area, pore size and distribution, are crucial for water evaporation, because the vapour generation happened on the interface between the water molecule and the air. The BET surface areas of the HPC samples with grinding time for 10 minutes (HPC-1), 20 minutes (HPC-2), 30 minutes (HPC-3) and 40 minutes (HPC-4) were $784 \mathrm{~m}^{2} \mathrm{~g}^{-1}, 922 \mathrm{~m}^{2} \mathrm{~g}^{-1}, 878 \mathrm{~m}^{2} \mathrm{~g}^{-1}$ and $1740 \mathrm{~m}^{2} \mathrm{~g}^{-1}$, respectively. More than $90 \%$ of the pore volume can be filled under a low gas pressure (about 0.05) shown in Fig. 3a. Most of the HPC samples have absorption volume of $0.4-0.48 \mathrm{~cm}^{3} \mathrm{~g}^{-1}$ (HPC-1/2/3), while the absorption volume of HPC-4 reached as high as $1.05 \mathrm{~cm}^{3} \mathrm{~g}^{-1}$. The $\mathrm{N}_{2}$ adsorption/desorption strip for HPC adopted a type I adsorption/desorption isothermal, indicating that the pore structure was dominated by microporous structure which also reflected by the nearly coincident adsorption/desorption distributions. The calculated pore size distribution indicated that the samples mainly consisted of the average size of $2.1 \mathrm{~nm}$ to $2.4 \mathrm{~nm}$. The HPC was also tested with mercury intrusion porosimetry considering the presence of macropores. As Fig. $\mathrm{S} 2 \uparrow$ shows, the total pore volume $4320 \mathrm{~mm}^{3} \mathrm{~g}^{-1}\left(4.32 \mathrm{~cm}^{3}\right.$ 

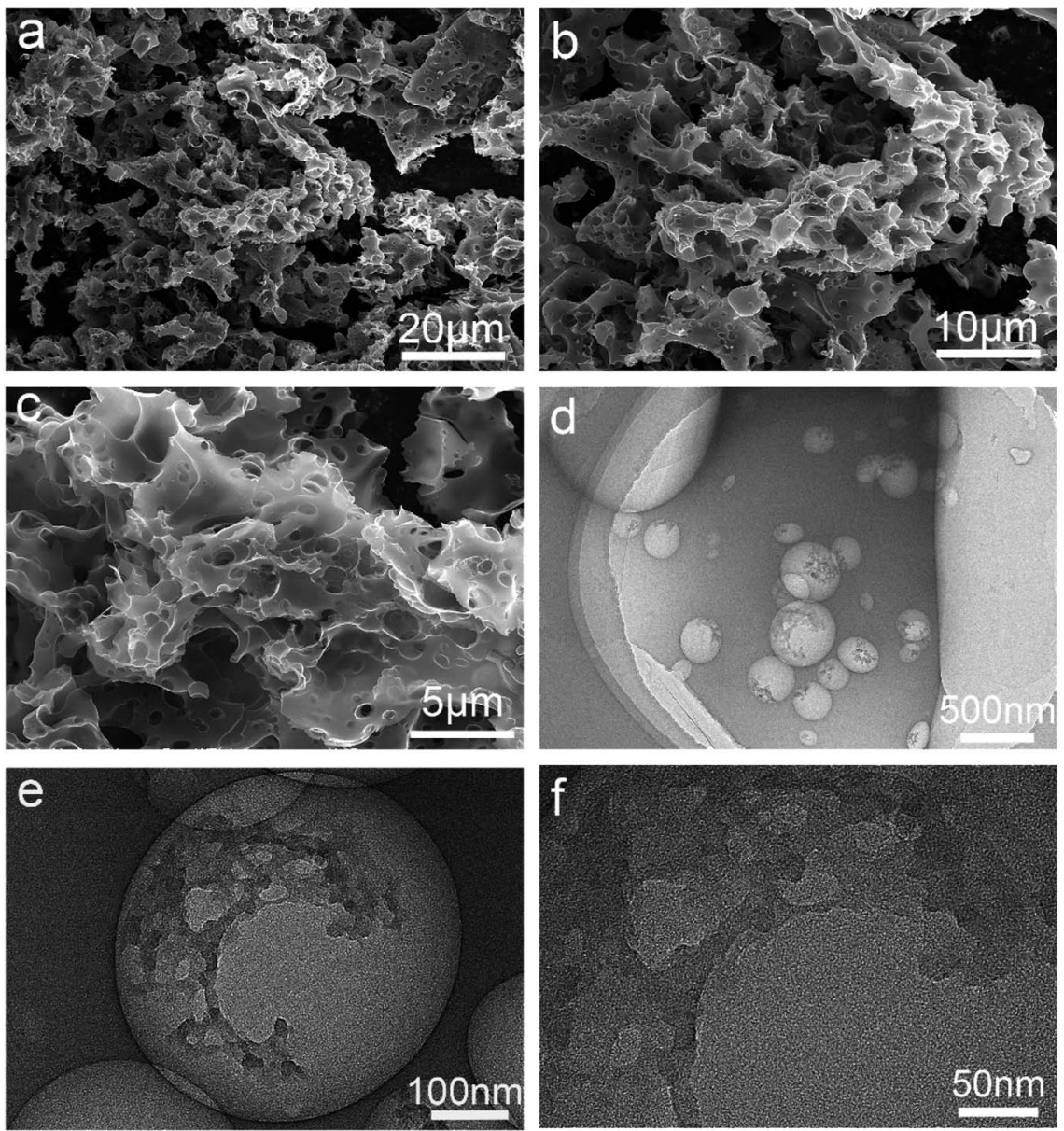

Fig. 2 Typical morphologies of the HPC samples. $(a-c)$ The Scanning Electron Microscope (SEM) images of the surfaces of HPC, revealing the interconnected macropores with the diameters from a few hundred nanometers to a few microns. ( $d-f$ ) Transmission electron microscope (TEM) images of thin layers of HPC, resolving the smaller, mesopores in the range of tens of nanometers $(\phi<50 \mathrm{~nm})$.

$\mathrm{g}^{-1}$ ), is compatible with BET results. The results of the mercury intrusion test indicate that the average pore diameter is about $1.7 \mu \mathrm{m}$, and the modal pore diameter is about $20 \mu \mathrm{m}$. The large specific surface areas and abundant hierarchical pores could enable faster photothermal energy capture, and greatly increase the sites and channels to generate water vapour.

The chemical states of the polymer-dehalogenation-induced carbon HPC were distinguished by X-ray Photoelectron Spectroscopy (XPS). Fig. 3b displays the XPS spectra of HPC. Strong C $1 \mathrm{~s}(285 \mathrm{eV})$ and $\mathrm{O} 1 \mathrm{~s}(532 \mathrm{eV})$ peaks were observed, and a weak signal of N 1s (401 eV) was detected (Fig. S3a, ESI†). The surface chemical element composition also can be derived from the XPS results (Fig. S3b, ESI $\dagger$ ), the amount of carbon (C) is about 91\%, oxygen $(\mathrm{O})$ is about $7.3 \%$ and the nitrogen $(\mathrm{N})$ atoms is about $1.5 \%$ in HPC-1/3/4 and one exception is the oxygen $(\mathrm{O})$ showed a certain increase reached about $12 \%$ in HPC-2. The nitrogen element is derived from the solvent dimethylformamide (DMF) and is incorporated and doping into the product HPC during dechlorination and carbonization. There is no $\mathrm{Cl}$ element detected. In Fig. 3c, the curve-fitted XPS spectrum of sample HPC-4 demonstrated that the content of $\mathrm{sp}^{2}$-hybridized graphitic carbon (C-C) accounted for over 55 at $\%$. The presence of $\mathrm{O}-/ \mathrm{N}-$ dopants $(\approx 26 \% \mathrm{C}-\mathrm{O}$ and $\approx 15.7 \% \mathrm{C}-\mathrm{N})$ in the $\mathrm{HPC}$ could enhance the hydrophilic properties.

The peaks in FTIR spectra (Fig. 3d) for HPC show that after the dechlorination reaction, the stretching vibrations of $\mathrm{O}-\mathrm{H}$ (around $\left.3500 \mathrm{~cm}^{-1}\right), \mathrm{C}=\mathrm{C}-\mathrm{H} \quad\left(\right.$ ca. $\left.2901 \mathrm{~cm}^{-1}\right), \mathrm{C}-\mathrm{H} \quad(c a$. $\left.2988 \mathrm{~cm}^{-1}\right), \mathrm{C}=\mathrm{C}\left(c a .1700 \mathrm{~cm}^{-1}\right)$ and $\mathrm{C}-\mathrm{OH}\left(1150 \mathrm{~cm}^{-1}\right)$ can be observed..$^{22,23}$ In addition, the stretching vibrations of $\mathrm{C} \equiv \mathrm{N}$ $\left(2210 \mathrm{~cm}^{-1}\right), \mathrm{C}-\mathrm{N}\left(1100 \mathrm{~cm}^{-1}\right)$ was also detected. The IR vibration signals from the $\mathrm{C}=\mathrm{C}-\mathrm{H}$ and $\mathrm{C}=\mathrm{C}$ in the precursors affirmed the proposed chemical reaction mechanism, as shown in Scheme 1. A hydrogen atom and one halide atom knocked off from the PVC chain resulted in $\mathrm{HCl}$ that was removed by KOH. The dehalogenation reaction is one of the typical elimination reactions, that forms double conjugated bonds along the long polymeric chain. ${ }^{22,24}$ This mechanism explains why the dechlorination could be activated by mechanochemical methods with the polar solvent DMF at room temperature. The Raman spectrums of the HPC samples are demonstrated in Fig. S4. $\dagger$ The $I_{\mathrm{D}} /$ $I_{\mathrm{G}}$ ratio decreases with the time increase of mechanochemical grinding, suggesting that the number of defects and disorder structures decrease. The thermal gravimetric analysis (TGA) curve of the HPC shown in Fig. S5, $\dagger$ reveals the chemical 

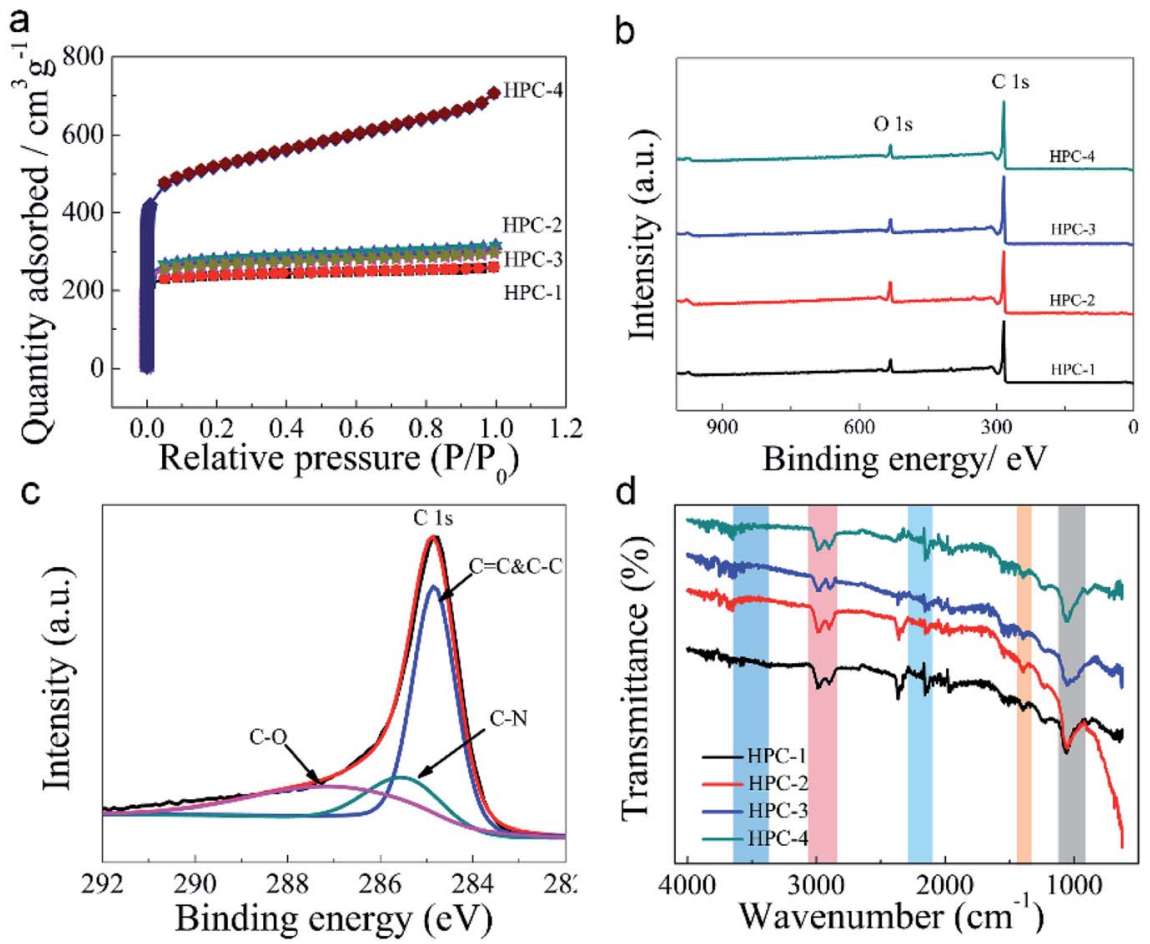

Fig. 3 Typical characterization analysis of the HPC samples. (a) The nitrogen adsorption-desorption isotherms. (b) The X-ray photoelectron spectroscopy (XPS) of HPC samples. (c) The fitted C 1s peaks of XPS spectra of HPC-4 sample. (d) The Fourier-transform infrared spectroscopy (FTIR) of HPCs.

reactions between the precursor and the $\mathrm{KOH}$. The weight loss of HPC was $84.07 \mathrm{wt} \%$ at $910^{\circ} \mathrm{C}$, which was possibly due to the thermal degradation of the carbon element. Due to the presence of oxygen-containing functional groups, the HPC exhibits strong hydrophilicity (shown in Video S1, ESI $\dagger$ ). The results of XPS and infrared characterizations demonstrate the presence of oxygen-containing functional groups, making the material be hydrophilic. The hydrophilic HPC offers the possibility of rapid conduction of water, and the porous structure of which utilizes capillary action to smoothly conduct water to the evaporating hot zone. The hierarchical porous structure discretizes water clusters, which promotes localized interface evaporation.

\section{Photothermal and water evaporation properties}

The carbons with unique pore structures together with low optical reflectivity, optimal chemical and surface properties are ideal for solar vapour generation applications. In solar energy water vapour generation area, the absorption of solar energy in

a)

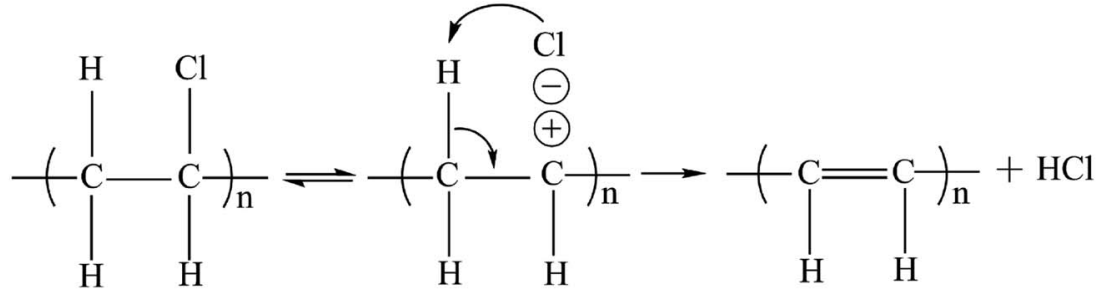

b)

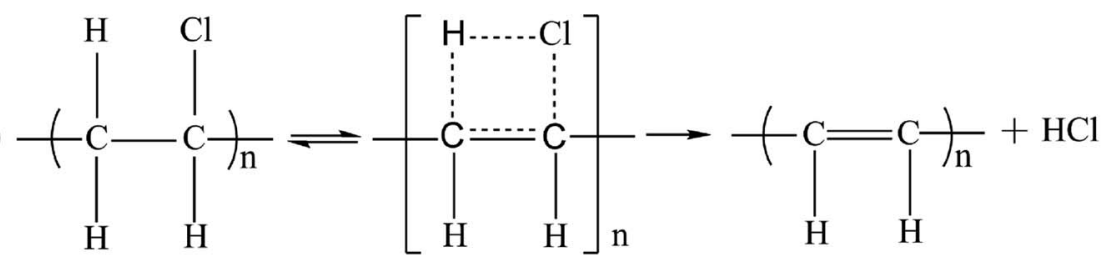

Scheme 1 Two possible mechanisms of the dechlorination of vinyl chloride (PVC) by the strong alkaline reagent $\mathrm{KOH}$. (a) The ionic and (b) the quasi-ionic mechanism for the elimination reaction. 
a broad solar spectrum is a critical factor. The optical performance of the HPC was detected using an ultraviolet-visiblenear-infrared (UV-Vis-NIR) spectrophotometer. As demonstrated in Fig. 4a, the sample HPC-4 with high $(\approx 91 \%)$ light absorption in the visible and near-infrared regions (250-2500 $\mathrm{nm}$ ) is higher than that of the samples HPC-1, HPC-2, HPC-3, which hand ground with shorter time (the reflectance showed in Fig. S6†). Normally, with the ground time increased, the light trapped in the HPC structure enhanced.

To characterize the performance of solar thermal evaporation, a series of experiments were performed under different solar light illumination using automatic recording software to record the evaporation of water and then calculated evaporation rates and energy conversion efficiencies. The experiments were carried on at room temperature of $28{ }^{\circ} \mathrm{C}$ and relative humidity of $43 \%$. The illumination intensity ranged from $1 \mathrm{~kW} \mathrm{~m}{ }^{-2}(1$ sun) to $5 \mathrm{~kW} \mathrm{~m}^{-2}$ (5 suns) and all the experiments last at least for 60 minutes at the stable stage. The solar vapour generation curves under 1 sun of the paper and HPC-4 coated on paper samples are shown in Fig. $4 \mathrm{~b}$. Due to the presence of HPC, the evaporation rate $\left(1.52 \mathrm{~kg} \mathrm{~m}^{-2} \mathrm{~h}^{-1}\right)$ is significantly increased under normal sunlight (1 sun), which is about 2.3 times of airlaid paper $\left(0.65 \mathrm{~kg} \mathrm{~m}^{-2} \mathrm{~h}^{-1}\right)$ and 3 times of blank water. Fig. $4 \mathrm{c}$ shows the typical evaporation curves of HPC-4 sample under different solar illumination conditions and with the simulated solar energy increased, the evaporation rates increased remarkably, it reached $4.91 \mathrm{~kg} \mathrm{~m}^{-2} \mathrm{~h}^{-1}$ at 3 suns, almost 9.8 times of the blank water, and further increased to $7.87 \mathrm{~kg} \mathrm{~m}^{-2}$
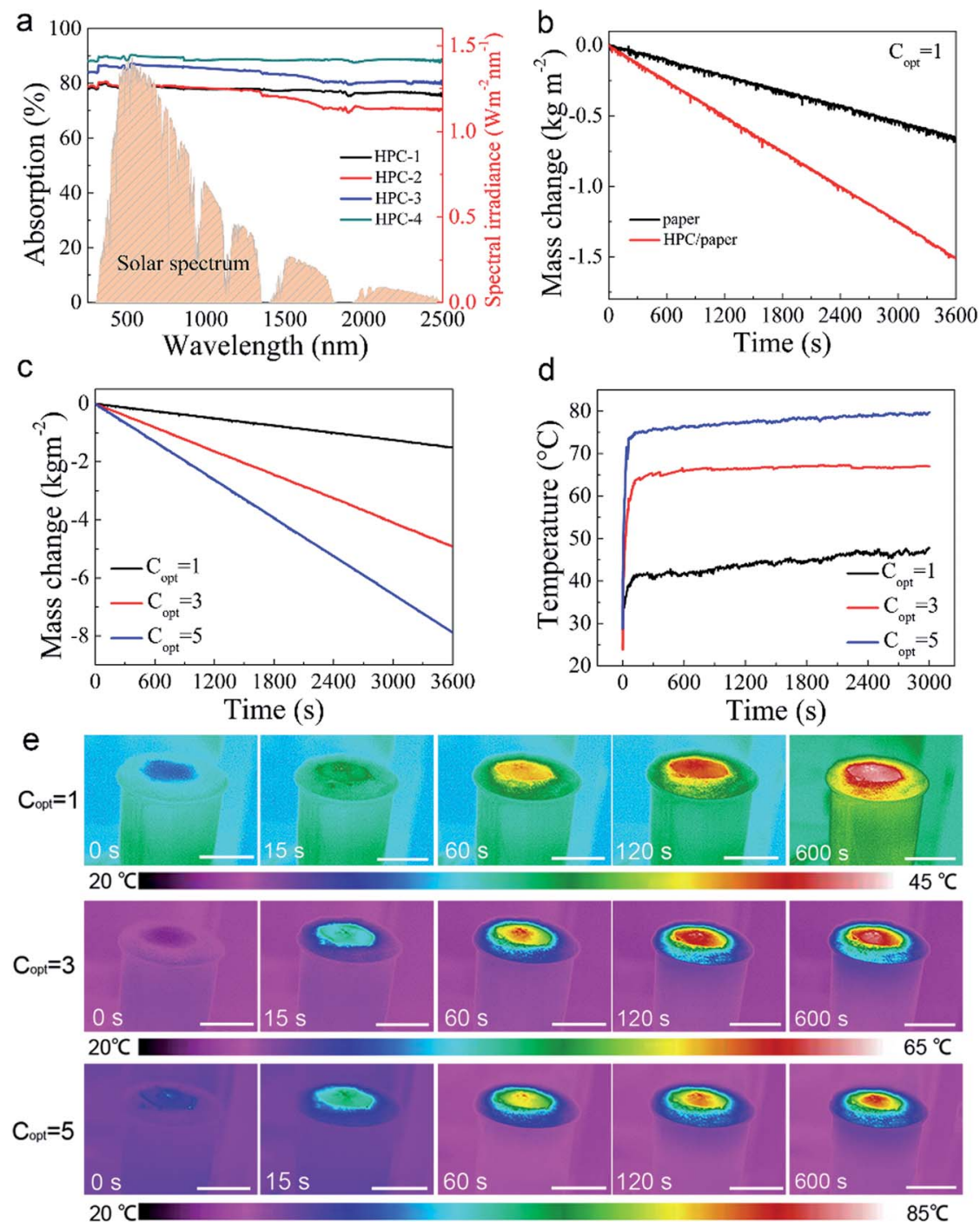

Fig. 4 The performance of the solar vapour generation of the HPC samples. (a) The UV-Vis-NIR optical spectrum of HPC samples showing the good optical absorption over a wide solar spectra from $250 \mathrm{~nm}$ to $2500 \mathrm{~nm}$. (b) The mass change vs. time curve of an HPC/paper device compared with the control experiment on the paper substrate. (c) The mass change vs. time curves of the HPC/paper device different solar intensities. (d) The change surface temperature of the device. (e) Sets of infrared (IR) camera photos illustrating the temperature and thermal energy distributions when the flexible HPC/paper device operated. The IR mapping photos were taken at $0 \mathrm{~s}, 15 \mathrm{~s}, 60 \mathrm{~s}, 120 \mathrm{~s}$ and $600 \mathrm{~s}$, indicating that the thermal energy field built up much faster (within 60 seconds). The temperature increased dramatically both upon time and enhanced solar illuminations. 
$\mathrm{h}^{-1}$ (15.7 times of the blank water evaporation rate) at 5 suns solar intensities. At nano/microstructure levels, the evaporation happens when the intermolecular bond between water molecules broke at the interfaces. ${ }^{25}$ With the absorbed solar energy increased, the evaporation rate will be enhanced, as being illustrated in Fig. 4c.

A fundamental question to answer is if the relatively small size of pores in carbon materials could limit the solar steam generation performances due to the limited capability of mass transfer. Therefore, a series of studies on the HPC device under different solar illumination have been executed, by mapping the temperature field to investigate solar thermal evaporation behaviour using an infrared camera. Fig. 4d shows the average temperature $\left(T_{\mathrm{av}}\right)$ of the HPC layer versus time. At the beginning of the experiment, the average temperature $T_{\mathrm{av}}$ of the HPC layer rises rapidly under simulated solar illumination and gradually stabilizes in a short time. According to the curves of the temperature-time, the temperatures of the HPC layer under 1 sun, 3 suns and 5 suns reach steady state at about $150 \mathrm{~s}, 120 \mathrm{~s}$ and $100 \mathrm{~s}$, respectively. According to the experimental results, after only 60 seconds under solar illumination, $T_{\mathrm{av}}$ of the HPC surface reached $43{ }^{\circ} \mathrm{C}, 65{ }^{\circ} \mathrm{C}$ and $78{ }^{\circ} \mathrm{C}$, respectively. This is much faster than those were observed in previous experiments using carbons with smaller pores. The infrared mapping images in Fig. 4e reveals that the temperature of the HPC layer is significantly higher than the ambient temperature, indicating the solar energy localized in the HPC layer and little heat is diffused to the bulk water. The maximum temperature on the surface of the device reached as high as $85{ }^{\circ} \mathrm{C}$ under concentrated sunlight illumination.
In Fig. 5a, the evaporation rates under different solar illumination showed a linear growth as the increase of sunlight intensity with increasing sunlight intensity with a calculated evaporation rate ratio of 1.59. Energy conversion efficiency is one of the important evaluation indexes for characterizing HPC materials to achieve water evaporation. The solar steam conversion efficiency of the HPC device for solar energy water vapour generation was calculated (the details are shown in the Experimental section). The efficiencies of the HPC device were calculated to be $81.2 \%, 97.9 \%$, and $95.8 \%$ at the solar density of $1 \mathrm{~kW} \mathrm{~m}^{-2}, 3 \mathrm{~kW} \mathrm{~m}^{-2}$, and $5 \mathrm{~kW} \mathrm{~m}^{-2}$ and together with previous reports summarized in Table 1 . The energy conversion efficiency is gradually increased and the slope of the rise is about 3.65. Obviously, as the solar energy density increases, the conversion efficiency gradually increases. Since evaporation of water occurs at the interface, the local limitation of heat can effectively vaporize water near the interface. In addition, HPC has a certain hydrophilic ability, so water molecules are distributed at the interface in the form of clusters. Under lowintensity solar radiation, water clusters require longer energy accumulation to achieve evaporation. As energy increases, the rate of evaporation of water molecules increases, and the time required becomes shorter. The hierarchical porous structure, which delocalizes the water clusters, provides a convenient condition for water conduction and steam escape. However, when the energy is not strong, the absorbed water content is relatively large, the evaporation rate is slightly lower, and also the energy conversion efficiency is lower. As the input energy is increased, the efficiency is improved (the details of calculation showed in ESI $7 \dagger$ ).
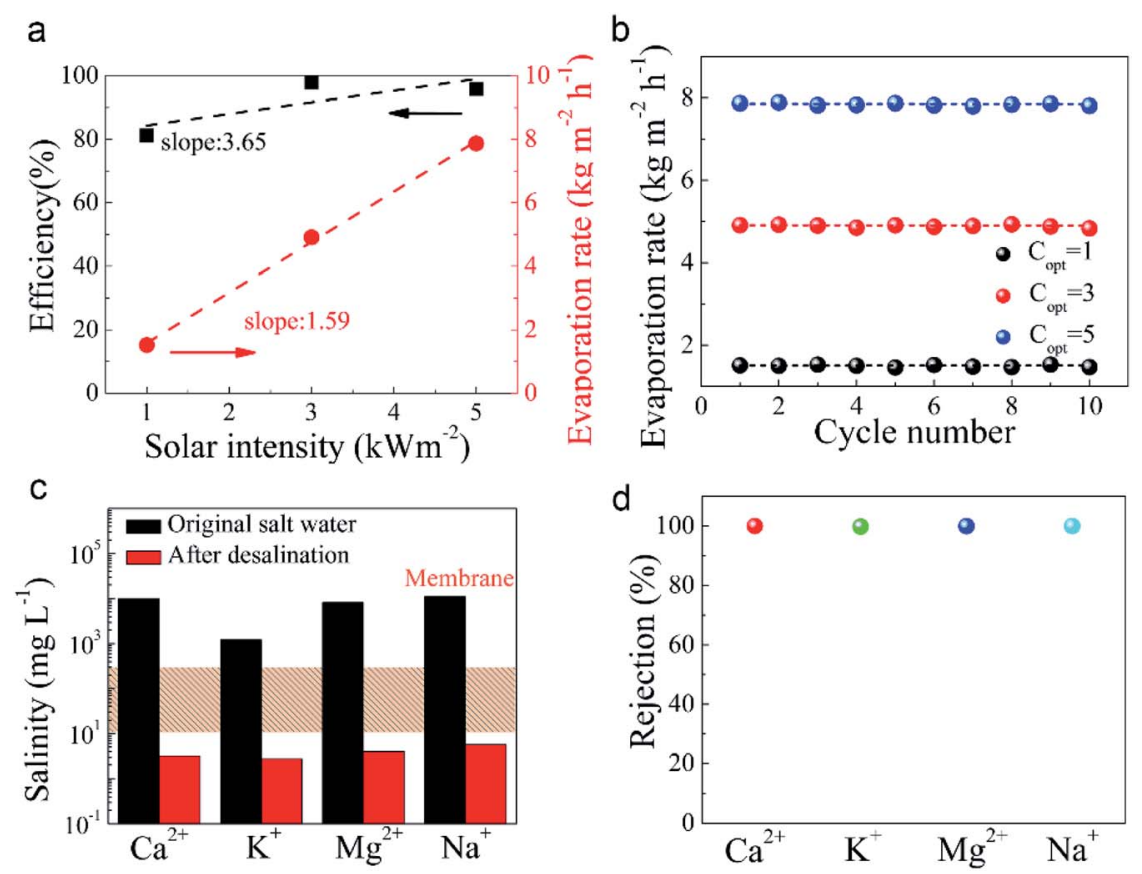

Fig. 5 (a and b) The energy efficiency, evaporation rate and stability of the devices, the linearity and stability confirm the effectiveness of large pores. (c) The salinity change between the original brine and the desalination water. (d) The salt rejection of the HPC for photothermal evaporation. 
Table 1 The photothermal device performances of the HPC materials from PVC, compared with results from various novel materials, the energy conversion and evaporation rates were all under solar intensity of $5 \mathrm{~kW} \mathrm{~m} \mathrm{~m}^{-2}$

\begin{tabular}{|c|c|c|c|c|c|}
\hline Sample & Carrier & $\begin{array}{l}\text { Solar absorption } \\
{[\%]}\end{array}$ & $\begin{array}{l}\text { Energy conversion } \\
{[\%]}\end{array}$ & $\begin{array}{l}\text { Evaporation rate } \\
{\left[\mathrm{kg} \mathrm{m}^{-2} \mathrm{~h}^{-1}\right]}\end{array}$ & References \\
\hline Pd-nanoparticles & Wood & 99 & 82 & 6 & 26 \\
\hline $\mathrm{Ti}_{2} \mathrm{O}_{3}$ nanoparticles & Cellulose membrane & 92.5 & 92.5 & 5.03 & 12 \\
\hline Carbon black & Porous paper & 98 & 88 & 6.24 & 27 \\
\hline Carbon & Wood & 95 & 85 & 6 & 6 \\
\hline Exfoliated graphite & Carbon foam & - & 72 & 5.2 & 15 \\
\hline CNT & Wood & 98 & 72 & 5.14 & 17 \\
\hline Graphene & Ni foam & $85-90$ & 93.4 & 6.9 & 30 \\
\hline HPC from PVC & Porous paper & 91 & 95.8 & 7.87 & This work \\
\hline
\end{tabular}

The macroporosity of the HPC allows satisfactory water inflow and vapour escape, and more importantly, as the sunlight increases, the escape of vapour and the supply from the bulk water can still be well matched. In contrast, the carbon with the structure of small-sized pores, as the sunlight increased, the evaporation rate does not increase linearly but appears saturated. ${ }^{1}$ The HPC devices are flexible, with carbons that have suitable pore structures which can absorb more sunlight energy for efficient evaporation and can easily achieve superior results over other novel materials.

A very impressive evaporation rate of $7.87 \mathrm{~kg} \mathrm{~m}^{-2} \mathrm{~h}^{-1}$, with a high energy conversion rate $95.8 \%$, have been achieved under 5 suns solar intensity. With the help of the thin, flexible HPC devices, the evaporation rate is as high as 15.7 times compared to the natural evaporation. Evaporation is one behavior that occurs at the interface, so it is easy to understand that a larger specific surface area can provide more active sites for interfacial evaporation of water, contributing to the rapid evaporation of water. Therefore, the increase in specific surface area will enhance the evaporation rate of water to some extent. The efficiency of the solar-vapour conversion $(95.8 \%)$ is also higher than other excellent reports in this field (Table 1). The unique structures of the carbons with large pores are extremely important and critical here to achieve such high evaporation rate and efficiency. The existence of the hierarchical porous structure is more suitable for the solar vapour generation than materials with small-sized mesoporous structures only. ${ }^{7}$ As the intensity of solar increases, the energy conversion efficiency of HPC gradually increases and is not limited. The hierarchical pore structure contains more large pores, the water mass transfer is enhanced and much faster, therefore the water vapor generated at the hot spots everywhere can quickly escape the surface by the connected macroporous structure. Because of such an ideal structure, the energy conversion efficiency remains high at high intensity of solar energy. Fig. 5b demonstrates the cycling durability of the HPC device under various of sunlight irradiation. The high robustness indicates that the materials have great potential to build high performance concentrated solar thermal powered steam generation devices.
It can be seen that within ten cycles ( 60 minutes per cycle), the evaporation rate is not significantly reduced but remains stable which is due to the well-designed structure. We configured a high concentration of brine solution with calcium ions (9801 $\mathrm{mg} \mathrm{L}^{-1}$ ), potassium ions (1231 $\mathrm{mg} \mathrm{L}^{-1}$ ), magnesium ions (8113 $\mathrm{mg} \mathrm{L}^{-1}$ ) and sodium ions $\left(11013 \mathrm{mg} \mathrm{L}^{-1}\right)$ as an example. As shown in Fig. 5c, after the desalination, the ions concentration of the collected condensed water were reduced to 3.2 $\left(\mathrm{Ca}^{2+}\right), 2.71\left(\mathrm{~K}^{+}\right), 4.02\left(\mathrm{Mg}^{2+}\right), 5.71\left(\mathrm{Na}^{+}\right) \mathrm{mg} \mathrm{L}^{-1}$, respectively. The desalination ability is superior to the membrane desalination methods. The salt removal rate reached above $99.5 \%$, as shown in Fig. 5d. In addition, the HPC materials derived from the PVC which is highly polluting to the environment have been produced by a simple preparation process with low energy consumption. These excellent features will be very beneficial to practical applications in the field of photothermal evaporation.

\section{Conclusion}

In summary, we demonstrated a new concept of low cost, flexible, hierarchical porous carbon coated on air-laid paper photothermal devices for high-performance solar steam generation. The feasibility of preparing multi-stage porous carbon by the dechlorination of PVC polymers with the help of alkaline materials and at low temperature provides a new way to highvalue utilization of recycled plastics. High BET $\left(1740 \mathrm{~m}^{2} \mathrm{~g}^{-1}\right)$ and optimal hierarchical pore structures (with pores diameters widely spread over $2 \mathrm{~nm}$ to $20 \mu \mathrm{m}$ ) were achieved by the mechanochemical dehalogenation of PVC followed by carbonization. These non-traditional carbon materials are produced through the dehalogenation of polymers, and by an inexpensive, simple and environmentally friendly method. More importantly, the HPC devices exhibit very high absorption of solar energy over a broad spectrum that leads to photothermal conversion efficiency, implying a great potential for practical applications. Together with perfect thermal management, the flexible HPC devices represent a new route towards large-scale manufacture and high efficiency of photothermal steam generation. Under the solar intensity of 5 suns, the evaporation rate reached a record evaporation rate of $7.87 \mathrm{~kg} \mathrm{~m}^{-2} \mathrm{~h}^{-1}$ and 
energy conversion efficiency of $95.8 \%$. This HPC materials with ideal hierarchical porous structures are attractive and promising for producing freshwater by evaporative desalination. This research will be useful and helpful for tackling the challenges of recycling and utilizing halogen-containing polymers, reducing the hazard pollutant chemicals such as dioxin. In view of the wide availability of the raw material PVC, this work will lead to large scale production of new porous green carbon materials that are ideal for efficient solar desalination applications.

\section{Conflicts of interest}

There are no conflicts to declare.

\section{Acknowledgements}

This work is supported by the Science and Technology Commission of Shanghai Municipality (STCSM) (Grant 17230732700), the Innovate UK (Grant 104013), the Institutional Strategic Grant - Global Challenges Research Fund (GCRF), that City, University of London, receives from Research England, UK Research and Innovation (UKRI).

\section{References}

1 G. Ni, G. Li, S. V. Boriskina, H. Li, W. Yang, T. Zhang and G. Chen, Steam generation under one sun enabled by a floating structure with thermal concentration, Nat. Energy, 2016, 1, 16126.

2 F. Liu, Y. Lai, B. Zhao, R. Bradley and W. Wu, Photothermal Materials and Structures for Efficient Solar Powered Steam Generation, Front. Chem. Sci. Eng., 2019, DOI: 10.1007/ s11705-019-1824-1.

3 N. Xu, X. Hu, W. Xu, X. Li, L. Zhou, S. Zhu and J. Zhu, Mushrooms as Efficient Solar Steam-Generation Devices, Adv. Mater., 2017, 29, 1606762.

4 X. Wu, G. Y. Chen, W. Zhang, X. Liu and H. Xu, A PlantTranspiration-Process-Inspired Strategy for Highly Efficient Solar Evaporation, Adv. Sustainable Syst., 2017, 1, 1700046.

5 Y. Wang, G. Sun, J. Dai, G. Chen, J. Morgenstern, Y. Wang, S. Kang, M. Zhu, S. Das, L. Cui and L. Hu, A HighPerformance, Low-Tortuosity Wood-Carbon Monolith Reactor, Adv. Mater., 2017, 29, 1604257.

6 H. Liu, C. Chen, G. Chen, Y. Kuang, X. Zhao, J. Song, C. Jia, X. Xu, E. Hitz, H. Xie, S. Wang, F. Jiang, T. Li, Y. Li, A. Gong, R. Yang, S. Das and L. Hu, High-Performance Solar Steam Device with Layered Channels: Artificial Tree with a Reversed Design, Adv. Energy Mater., 2018, 8, 1701616.

7 F. Liu, B. Zhao, W. Wu, H. Yang, Y. Ning, Y. Lai and R. Bradley, Low Cost, Robust, Environmentally Friendly Geopolymer-Mesoporous Carbon Composites for Efficient Solar Powered Steam Generation, Adv. Funct. Mater., 2018, 28, 1803266.

8 J. Fang, Q. Liu, W. Zhang, J. Gu, Y. Su, H. Su, C. Guo and D. Zhang, Ag/diatomite for highly efficient solar vapor generation under one-sun irradiation, J. Mater. Chem. A, 2017, 5, 17817-17821.
9 L. Zhou, S. Zhuang, C. He, Y. Tan, Z. Wang and J. Zhu, Selfassembled Spectrum Selective Plasmonic Absorbers with Tunable Bandwidth for Solar Energy Conversion, Nano Energy, 2017, 32, 195-200.

10 Y. Liu, S. Yu, R. Feng, A. Bernard, Y. Liu, Y. Zhang, H. Duan, W. Shang, P. Tao, C. Song and T. Deng, A Bioinspired, Reusable, Paper-based System for High-performance Largescale Evaporation, Adv. Mater., 2015, 27, 2768-2774.

11 L. Zhou, Y. Tan, J. Wang, W. Xu, Y. Yuan, W. Cai, S. Zhu and J. Zhu, 3D self-assembly of aluminium nanoparticles for plasmon-enhanced solar desalination, Nat. Photonics, 2016, 10, 393-398.

12 J. Wang, Y. Li, L. Deng, N. Wei, Y. Weng, S. Dong, D. Qi, J. Qiu, $\mathrm{X}$. Chen and $\mathrm{T}$. Wu, High-Performance Photothermal Conversion of Narrow-Bandgap $\mathrm{Ti}_{2} \mathrm{O}_{3}$ Nanoparticles, Adv. Mater., 2017, 29, 1603730.

13 R. Li, L. Zhang, L. Shi and P. Wang, MXene $\mathrm{Ti}_{3} \mathrm{C}_{2}$ : An Effective 2D Light-to-Heat Conversion Material, ACS Nano, 2017, 11, 3752-3759.

14 Y. Ito, Y. Tanabe, J. Han, T. Fujita, K. Tanigaki and M. Chen, Multifunctional Porous Graphene for High-Efficiency Steam Generation by Heat Localization, Adv. Mater., 2015, 27, 43024307.

15 H. Ghasemi, G. Ni, A. M. Marconnet, J. Loomis, S. Yerci, N. Miljkovic and G. Chen, Solar steam generation by heat localization, Nat. Commun., 2014, 5, 4449.

16 X. Yang, Y. Yang, L. Fu, M. Zou, Z. Li, A. Cao and Q. Yuan, An Ultrathin Flexible 2D Membrane Based on Single-Walled Nanotube- $\mathrm{MoS}_{2}$ Hybrid Film for High-Performance Solar Steam Generation, Adv. Funct. Mater., 2018, 28, 1704505.

17 C. Chen, Y. Li, J. Song, Z. Yang, Y. Kuang, E. Hitz, C. Jia, A. Gong, F. Jiang, J. Y. Zhu, B. Yang, J. Xie and L. Hu, Highly Flexible and Efficient Solar Steam Generation Device, Adv. Mater., 2017, 29, 1701756.

18 Z. Yin, H. Wang, M. Jian, Y. Li, K. Xia, M. Zhang, C. Wang, Q. Wang, M. Ma, Q. S. Zheng and Y. Zhang, Extremely Black Vertically Aligned Carbon Nanotube Arrays for Solar Steam Generation, ACS Appl. Mater. Interfaces, 2017, 9, 28596-28603.

19 L. Zhu, M. Gao, C. K. N. Peh, X. Wang and G. W. Ho, SelfContained Monolithic Carbon Sponges for Solar-Driven Interfacial Water Evaporation Distillation and Electricity Generation, Adv. Energy Mater., 2018, 8, 1702149.

20 X. Gao, H. Ren, J. Zhou, R. Du, C. Yin, R. Liu, H. Peng, L. Tong, Z. Liu and J. Zhang, Synthesis of Hierarchical Graphdiyne-Based Architecture for Efficient Solar Steam Generation, Chem. Mater., 2017, 29, 5777-5781.

21 G. Zhang, L. Wang, Y. Hao, X. Jin, Y. Xu, Y. Kuang, L. Dai and X. Sun, Unconventional Carbon: Alkaline Dehalogenation of Polymers Yields N-Doped Carbon Electrode for HighPerformance Capacitive Energy Storage, Adv. Funct. Mater., 2016, 26, 3340-3348.

22 Y. Xie, Q. Huang and B. Huang, Chemical reactions between calcium carbide and chlorohydrocarbon used for the synthesis of carbon spheres containing well-ordered graphite, Carbon, 2010, 48, 2023-2029. 
23 P. Zhao, Z. Li, T. Li, W. Yan and S. Ge, The study of nickel effect on the hydrothermal dechlorination of PVC, $J$. Cleaner Prod., 2017, 152, 38-46.

24 Y. Shindo and T. Hirai, Dehydrohalogenation of Polyvinylchloride in Tetrahydrofuran Solution with Alcoholic KOH, Macromol. Chem. Phys., 1972, 155, 1-16.

25 Y. Nagata, K. Usui and M. Bonn, Molecular Mechanism of Water Evaporation, Phys. Rev. Lett., 2015, 115, 236102.

26 M. Zhu, Y. Li, F. Chen, X. Zhu, J. Dai, Y. Li, Z. Yang, X. Yan, J. Song, Y. Wang, E. Hitz, W. Luo, M. Lu, B. Yang and L. Hu, Plasmonic Wood for High-Efficiency Solar Steam Generation, Adv. Energy Mater., 2018, 8, 1701028.

27 Z. Liu, H. Song, D. Ji, C. Li, A. Cheney, Y. Liu, N. Zhang, X. Zeng, B. Chen, J. Gao, Y. Li, X. Liu, D. Aga, S. Jiang, Z. Yu and Q. Gan, Extremely Cost-Effective and Efficient Solar Vapor Generation under Nonconcentrated
Illumination Using Thermally Isolated Black Paper, Global Challenges, 2017, 1, 1600003.

28 F. Jiang, H. Liu, Y. Li, Y. Kuang, X. Xu, C. Chen, H. Huang, C. Jia, X. Zhao, E. Hitz, Y. Zhou, R. Yang, L. Cui and L. Hu, Lightweight, Mesoporous, and Highly Absorptive AllNanofiber Aerogel for Efficient Solar Steam Generation, ACS Appl. Mater. Interfaces, 2017, 10, 1104-1112.

29 J. Huang, Y. He, M. Chen, B. Jiang and Y. Huang, Solar Evaporation Enhancement by a Compound Film Based on $\mathrm{Au} @ \mathrm{TiO}_{2}$ Core-Shell Nanoparticles, Sol. Energy, 2017, 155, 1225-1232.

30 H. Ren, M. Tang, B. Guan, K. Wang, J. Yang, F. Wang, M. Wang, J. Shan, Z. Chen, D. Wei, H. Peng and Z. Liu, Hierarchical Graphene Foam for Efficient Omnidirectional Solar-Thermal Energy Conversion, Adv. Mater., 2017, 29, 1702590. 